\title{
Os Territórios de Ação Política de Jovens do Movimento Hip-Hop
}

\author{
Mônica Rodrigues Costa* \\ Jaileila de Araújo Menezes**
}

\begin{abstract}
Resumo: O movimento Hip-Hop assenta-se comumente em territórios periféricos, locus de sua ação político-cultural, e dele fazem parte, em sua maioria, jovens negros e pobres. Este artigo problematiza as noções de comunidade e território, considerando os níveis de diálogo e comunicação mobilizados por esse movimento, com o propósito de alterar as desigualdades em que os jovens estão imersos. Resulta de um estudo etnográfico em um bairro periférico da cidade onde atua um coletivo do movimento. A conclusão do estudo é a de que, apesar das dificuldades para a ação política, os jovens do movimento Hip-Hop garantem a formação de um sentimento de comunidade entre os sujeitos envolvidos, caracterizado por laços sociais de pertencimento.

Palavras-chave: Território; movimento Hip-Hop; juventude; desigualdades sociais.
\end{abstract}

\begin{abstract}
The Hip-Hop movement is usually based on peripheral regions, carried out mostly by young black and poor. The article questions the notions of community and territory, considering the level of dialogue/communication raised by this movement, in order to change the inequalities in which young people are immersed. It results from an ethnographic study outskirts Rio de Janeiro. The outstanding conclusion is that despite the difficulties for political action, the youth of the hip-hop fosters the growing of feelings of community membership, political-cultural ties and social bonds within the territory they live.

Keywords: Territory; Hip-Hop movement; youth; social inequalities.
\end{abstract}

\section{Contextualizando o Movimento}

O movimento Hip-Hop originou-se nos anos 1970, em Nova lorque, EUA, nos bairros suburbanos do Bronx, Harlem, Brooklyn e Queens, e é formado,

\footnotetext{
* Assistente Social. Mestre em Ciência Política. Doutora em Serviço Social pela Universidade Federal de Pernambuco. Professora adjunta do Departamento de Serviço Social da U̧niversidade Federal de Pernambuco. Endereço postal: Rua Professor Moraes Rego, 1.235, Cidade Universitária, Recife, Pernambuco, CEP: 506070.901. Endereço eletrônico: morodrigues.costa@gmail.com.
}

** Psicóloga. Mestre e doutora em Psicologia pela Universidade Federal do Rio de Janeiro. Professora adjunta do Departamento de Psicologia da Universidade Federal de Pernambuco. Endereço postal: Rua Professor Moraes Rego, 1.235, Cidade Universitária, Recife, Pernambuco, CEP: 506070.901. Endereço eletrônico: jaileila@terra. com.br.

${ }^{1}$ O termo hip-hop foi criado em meados de 1968 por Afrika Bambaata. Ele teria se inspirado em uma dança popular na época, que era saltar (hop) movimentando os quadris (hip). 
sobretudo, por jovens negros e latinos. Sua criação recebeu contribuições de afroamericanos e imigrantes latinos, que misturaram o dub jamaicano, o soul, o jazz e o funk com os mais variados estilos musicais e transformaram essas tradições em um estilo musical e um comportamento cultural que incorporam expressões corporais e artísticas diversas (rap, break, grafite).

Com forte influência dos movimentos negros da década de 1960 e da cultura de rua, o movimento Hip-Hop construiu ética e estética inovadoras para a juventude pobre, moradora das periferias das cidades, com o intuito de se colocar como alternativa ao modo de vida dos jovens, valorizar a cultura popular e as diferenças étnico-raciais. Esses subúrbios constituem verdadeiros guetos, nos quais incide todo tipo de problema: pobreza, violência, racismo, tráfico de drogas, carência de acesso a bens e serviços. Em termos gerais, anteriormente, os jovens tomavam as ruas como domínio territorial e espaço de lazer, com as demarcações de território por suas gangues, e afiliar-se a elas significava lutar pela circulação e ocupação desses espaços públicos. Contudo, confrontos violentos entre as gangues causavam a morte de muitos deles.

Para atrair os jovens nessas condições, Afrika Bambaata, um DJ do Bronx, inseriu na cultura das gangues a dança (breakin', up rockin', poppin' e lockin), a arte plástica (graffiti), a discotecagem $(d j)$, bem como rimas improvisadas $(m c)$ e compostas (rappers). Ele associou a essas atividades o elemento conhecimento, com conteúdos e ações educativas voltados para a difusão de valores como paz, união, liberdade e justiça. Visava a reduzir a violência entre as gangues e resolver suas diferenças mediante expressões artísticas, além de preservar a história de seus antepassados e imprimir uma nova cultura urbana.

Esse elemento, nomeado como conhecimento, visa a preservar a história dos antepassados e a conexão dos jovens envolvidos com as lutas por direitos civis travadas pelo povo afro-americano via construção de uma nova cultura, que favoreça a tomada de consciência da desigualdade social e a luta contra as discriminações e desigualdades. Desse modo, as expressões culturais no movimento Hip-Hop ganharam feições de protesto, demonstrando capacidade de organização dos grupos e de atuação comunitária, além de constituirem uma relação ambígua com a indústria cultural.

A principal porta de entrada do Hip-Hop no Brasil, no início dos anos 1980, foram os chamados bailes Black, onde se ouviam músicas soul e funk. Seu primeiro registro no cenário musical data de 1988, em São Paulo, com uma coletânea intitulada "Hip-Hop Cultura de Rua". Mas, ainda na primeira metade da década de 1980, começaram a surgir os rappers brasileiros pioneiros, como Thaíde e DJ Hum, MC Jack, Racionais MC's e também os primeiros dançarinos de break, que se reuniam em locais como a Rua 24 de maio e a estação São Bento do metrô, em São Paulo (FOLHATEEN, 2006).

No final dos anos 1980, o rap já era a trilha sonora da periferia brasileira, por conter mensagens de protesto sobre injustiças do cotidiano, que se assemelha ao dos jovens negros e pobres dos grandes centros urbanos do país. Na mesma época, mais precisamente em 1989, foi criado o MH2O - Movimento Hip-Hop Organizado -, com o intuito de divulgar o movimento. 
O hip-hop e seus elementos compõem, assim, um campo político capaz de fazer apelo às mais diversas linguagens, sonoro-auditiva (rap/dj), gestual (break) e visual (grafite), seus valores e filosofia aos poucos vão sendo compreendidos e incorporados pelos jovens urbanos e pobres, construindo sua identidade como um estilo cultural que tem origem nas ruas das cidades e que expressa o cotidiano das periferias (COSTA e MENEZES, 2007, p. 5).

As diversas possibilidades de expressão artístico-cultural - que viabilizam e estimulam a criatividade e a inserção de elementos culturais das realidades que esses jovens vivem - tornaram-se potenciais vocalizadoras das demandas contestatórias dos jovens pobres à sociedade (COSTA e MENEZES, 2007). O Hip-Hop configurou-se como um estilo de vida e uma atitude, que expressam posicionamentos em relação à realidade que os cerca, a qual os expõe, sobretudo, à violência, às drogas e à falta de perspectivas. É a voz, o gesto e a ação do próprio sujeito no mundo.

Assim, o movimento Hip-Hop explicita as desigualdades sociais vivenciadas pelos jovens das camadas pobres da cidade. Ao ocupar o espaço público com suas expressões artísticas, esses sujeitos inflexionam a relação periferia-centro, trazem à tona as relações de poder implícitas nessa polaridade, que circunscreve não apenas a ocupação do espaço urbano, mas implica o acesso diferenciado aos bens materiais e simbólicos da ordem da cidadania.

A relação periferia-centro se complexifica a partir da expansão das favelas nas grandes e médias cidades, que cresceram desordenadamente a partir dos anos 1950, por conta do grande fluxo migratório campo-cidade, que tornou ainda mais visíveis os já presentes conflitos de classe. Contraposta a um determinado ideal de urbano, a favela passou a ser considerada um problema a ser combatido, pois ela era externa ao território reconhecido como o lugar, por excelência, de exercício da cidadania (SILVA e BARBOSA, 2005).

A segregação urbana que configura a lógica da ocupação do espaço territorial e é geradora das favelas aciona um conjunto de significados socialmente consensuais. Como afirma Silva, "a favela é definida pelo que ela não é ou pelo que não tem", é um espaço destituído de infraestrutura, com diferentes níveis de violência, "[...] sem ordem, sem lei, sem regras, sem moral, enfim, expressão do caos" (2007, p. 211). No caso da cidade de Recife e de sua organização espacial, essa denominação inclui áreas centrais onde se apresentam favelas e palafitas, entre outros tipos de urbanidade, nas quais predomina a lógica da pobreza e da falta.

Ao agregar tais destituições, a favela desponta como marcação pejorativa, atribuída aos que nela habitam, o que proporciona função estratégica à designação "comunidade", que tem sido comumente utilizada por esses habitantes como modo de enfrentar o estigma e as discriminações - com o sentido de valor mais positivo para a sociabilidade periférica. Esse uso corrente e estratégico do termo, por parte dos moradores, tem correlato na discussão de teóricos como Bauman (2003), que definem comunidade como condição de segurança, já que remete à ideia de responsabilidades, compromissos e engajamentos por parte de seus membros. Tais elementos transmutam estigmatização em agentividade positiva. Neste artigo, a 
proposta é articular esses conceitos - território e comunidade -, que são tomados aqui para além de uma delimitação geográfica, a fim de refletir acerca da potência política dos sujeitos, em face das desigualdades nas quais eles estão imersos.

\section{Movimento Hip-Hop em Recife: Recortes de uma Cena}

O registro de informações da pesquisa "A arte na política: um estudo do movimento Hip-Hop na cidade de Recife" (COSTA e MENEZES, 2007) afirma que Recife apresenta muitos elementos confluentes para o assentamento do Hip-Hop. Essa metrópole conta com 94 bairros, muitos constituídos a partir de ocupações, que estão atualmente agrupados em seis regiões administrativas, nas quais se podem situar 66 Zonas Especiais de Interesse Social (ZEIS), que resultam de uma história de luta pelo direito à cidade. Em síntese, é uma cidade com significativo cinturão periférico, local por excelência de origem de muitos jovens integrantes do movimento HipHop.

Nesse cinturão periférico, destaca-se uma população predominantemente jovem, na faixa etária de quinze a trinta anos, cujo índice de mortalidade, segundo o Mapa da violência IV, realizado pela Unesco (2005), tem aumentado sobremaneira nos últimos anos e revelado, no caso de Recife, crescimento dos óbitos por causas externas, com maior ocorrência de homicídios. Essa situação revela mútua influência entre os índices de violência e as situações de vulnerabilidade e exclusão social.

Os jovens pobres e residentes nas periferias de Recife enfrentam todo o tipo de obstáculos socioeconômicos. Fazem parte de seu cotidiano a violência policial, a discriminação, a dificuldade de acesso a bens e serviços, a restrição de sua mobilidade na cidade. Toma-se aqui a periferia como conceito relacional, "[...] fruto de um processo de atualização do mundo moderno-colonial, que foi produzido/ criado" (RODRIGUES, 2003, p. 22) por desigualdade política, social, econômica e racial. Esse processo se organizou a partir de relações hegemônicas entre centro e periferias, configurando, portanto, relações dinâmicas de disputas sociais.

A vivência das desigualdades se visibiliza na vida dos jovens via conflitos e tensões. Eles entram no mundo do trabalho precocemente, sem qualificação, o que exige maior investimento criativo para se "garantir" no mercado informal. Em função desse conjunto de dificuldades, eles também apresentam uma relação descontínua com a instituição escola.

Esse cenário de restrições e vulnerabilidades se agravou nas cidades da América Latina a partir da década de 1990, com a erosão do poder do Estado como promotor do desenvolvimento e do bem-estar social. Em nome da modernização e da entrada na era da globalização, o desenvolvimento socioeconômico neoliberal tem, desde então, caminhado no sentido de agravar os problemas da pobreza e da desigualdade social gerados pela concentração de renda.

Segundo o relatório da Unesco (2003) sobre desenvolvimento juvenil, a alta concentração de renda no Brasil reforça a vulnerabilidade dos jovens pobres e provoca diferenças no acesso a bens e serviços sociais básicos, principalmente se considerando os residentes das regiões Norte e Nordeste. A juventude passa a ser vista como grupo social que dramatiza a segregação urbana e demanda a elaboração de políticas públicas. 
Tais políticas deveriam colaborar para a alteração desse quadro. No entanto, restringem-se a qualificar esses jovens para o empreendedorismo e a mobilização comunitária, utilizando-se da lógica da autonomia e da inclusão para responsabilizálos pelas modificações de sua situação de vida e, quiçá, da coletividade. Sendo assim, além de viverem em condições adversas e precárias em seus territórios, em termos de equipamentos mínimos de saúde, lazer e saneamento, ou seja, sem a presença efetiva do Estado, os jovens ainda são apontados como atores sociais chave de mobilização com vistas à resolução desses problemas.

É fato que, na História brasileira, existe uma tradição de engajamento juvenil que levou várias gerações à participação político-social, inclusive, com envolvimento em movimentos sociais diversos. Nossa preocupação é que essa experiência social sirva a uma lógica perversa. Parodiando o título do livro de Rezende (1987), "ninguém pode servir a dois senhores", o que tem se caracterizado como ação política dos jovens, ou seja, ser utilizados como substituição da ação estatal.

No caso dos jovens vinculados ao movimento Hip-Hop, o exercício reflexivo acerca de suas condições de vida, via elementos artísticos dessa cultura (break, dj, rap, grafite), propicia a elaboração de posicionamentos críticos a esse tipo de responsabilidade que o Estado lhes imputa. Todo o discurso do protagonismo juvenil, nesses termos, merece ser repensado em função de sua estratégia de culpabilização dos jovens pobres e de sua insuficiência para promover efetiva transformação social. Afinal, o que é de ordem coletiva e de natureza pública é da responsabilidade do Estado.

Essa percepção crítica do jogo político é acionada por um elemento específico do movimento Hip-Hop: o conhecimento. Ele instrumentaliza para o exercício da política - então, possibilita aos jovens confrontar versões sobre as situações de desigualdade social. Esse elemento é o eixo articulador dos demais, e garante o engajamento e a participação social politicamente orientada dos jovens.

Consideramos a referência a esse elemento como diferencial na atuação dos diversos grupos existentes na cidade, uma vez que encontramos os que se afirmam como grupos culturais e outros que se definem pelas ações que desenvolvem nas periferias ou junto a outros jovens. Tais ações são caracterizadas pela crítica à vacância de políticas públicas voltadas ao segmento e à coletividade, o que demarca um campo de ação político-social atento à garantia dos direitos sociais, em oposição à responsabilização individual.

O engajamento político-social tem como propósito especial transformar a realidade dos jovens envolvidos no movimento e de outros jovens pobres que se encontram nas mesmas condições de existência. Observa-se a preocupação com a conscientização de crianças, adolescentes e jovens, via expressões culturais do movimento, como política alternativa às formas de viver comumente presentes em seu cotidiano.

Os depoimentos dos integrantes do movimento Hip-Hop dão conta da forma peculiar como essa expressão cultural adentrou o Recife. Inicialmente, a adesão foi marcada pelo enfoque expressivo (com destaque para a dança e a música), que formou toda a primeira geração de participantes. Tal geração, ao acessar o elemento conhecimento, apropriou-se da trajetória histórica do movimento e de sua dimensão política. 
A conexão com esse conhecimento redimensiona a relação dos jovens locais com o Hip-Hop e fortalece a vertente política de viés comunitário. Quer dizer, eles buscam agir e se organizar comunitariamente mobilizando os habitantes locais do bairro ou favela. Destacam-se duas organizações que efetivaram essa prática: a Associação Metropolitana de Hip-Hop e a Rede de Resistência Solidária. Ambas congregam vários grupos e possibilitam qualificar potenciais criativos por meio da cultura hip hop, inserindo esses jovens em espaços sociais estratégicos.

O caráter excludente das políticas sociais públicas e a ineficiência de algumas delas para garantir e fomentar o desenvolvimento das capacidades dos jovens pobres da cidade, moradores das periferias e favelas, mobilizaram parcela do movimento Hip-Hop a adotar como pressuposto a necessidade de agir localmente no enfrentamento dos condicionantes sociais que restringem as possibilidades sociais dos jovens na sociedade.

Apesar disso, ou justamente por isso, os jovens buscam positivar seus territórios, recorrendo a denominações que indiquem os esforços empreendidos para qualificar os espaços que habitam. Na maioria das vezes, os participantes do movimento Hip-Hop denominam suas localidades como comunidades. Identificamos poucas referências ao termo "favela", bem como pouca utilização dele, o que nos fez refletir sobre as noções de território para problematizá-las - favela ou comunidade.

Percebemos que o centro da ação política do movimento Hip-Hop na cidade do Recife ratifica as pesquisas que indicam sua territorialidade. A valorização do pertencimento à periferia e o desenrolar de suas práticas nesse território parece que organizam essa ideia e sentido de comunidade àqueles que compartilham o espaço físico e, nele, a produção de bens simbólicos e materiais.

Nessa discussão, Haesbaert (2007) localiza a contradição dos tempos atuais, relativa ao peso que teve o território nas duas últimas décadas, em meio à defesa de um mundo desterritorializado. Essa defesa é feita em um contexto marcado pela globalização e pelo avanço das tecnologias de informação e dos meios de comunicação, que apontam um mundo organizado de modo reticular ou como o mundo das redes. As narrativas se deslocam às vezes para a defesa do fim do território outras tantas para a exaltação da hipertrofia espacial no contexto social do nosso tempo, sob o domínio do presente e da sincronicidade" (HAESBAERT, 2007, p. 44).

Para ressituar o debate sobre território (ARAÚJO, 2003; HAESBAERT, 2007; SANTOS, 1998; 2001), como ponto de partida, encontramos pelos menos duas vertentes clássicas: uma que privilegia a dimensão material, sobretudo no sentido de valor e de poder relativos ao território; e outra que valoriza aspectos simbólicoculturais que implicam a representação da identidade cultural, que extrapola o posicionamento topográfico. Para nós, o território é demarcado por um caráter relacional. Tratar o território como campo relacional é considerá-lo um campo de forças, de relações de poder espacialmente delimitadas em um contexto específico. Nessa perspectiva, evita-se a desgeografização e a sociologização do debate, que possam anular o espaço vivido e cheio de relações sociais.

No caso do movimento Hip-Hop, podemos perceber o poder do laço territorial (BONNEMAISON e CAMBREZY, 1996), no qual se desenvolve um campo re- 
lacional, orientado afetiva, simbólica, espiritual, ética e materialmente. É recorrente o uso do termo "irmão" para designar proximidade, um compartilhar de modo e estilo de vida, de gostos e projetos que são simultaneamente individuais e coletivos, por jo-vens que têm em comum forte identificação como moradores de periferia, seja do Recife, de outra parte do Brasil ou do mundo. Como diz a letra, "periferia é periferia em qualquer lugar" (RACIONAIS MC's, 1998) ou, como no rap local, "mais uma vez de novo, só pelo povo, da periferia, somos maioria, no jogo" (APS).

Os trechos de rap acima informam tanto uma territorialidade como um reconhecimento de lugares sociais. Esse discurso valoriza a articulação dos projetos individuais e coletivos, cuja liga ética referente ao campo de princípios do movimento Hip-Hop são: conhecimento, entendimento, liberdade, justiça, igualdade, sabedoria, paz, unidade, amor, respeito, trabalho e diversão. Esses princípios forjam os vínculos e os compromissos entre os membros, produzindo algo comum, o que fortaleceria a ideia de comunidade.

Nos estudos sobre comunidade, podemos localizar uma visão positivada, que valoriza o consenso, o acordo em prol do bem coletivo, lugar de acolhimento e segurança dos membros desse movimento, como defende Arruda, para quem a comunidade é "um conjunto de pessoas que compartilham um projeto em comum, valores, ideais e práxis em comum" (2001, p. 162). Essa perspectiva apresenta o elemento ético na concepção de comunidade e obscurece a presença de possíveis conflitos, pois entendemos que ser uma comunidade não significa ausência de disputas.

Há encontro entre essa perspectiva e o que pensa Bauman (2003), quando o autor ratifica o sentido de comunidade como segurança e proteção aos indivíduos. No entanto, ele avança na discussão, ao propor a desnaturalização e a desterritorialização desse conceito. Nesses termos, não há necessidade natural de existência de comunidade, ela é acionada em situações em que se configuram desvantagens e desigualdades sociais. Essas situações são recorrentes nas sociedades meritocráticas como a brasileira, nas quais os fracos precisam de coletividade, pois individualmente não dispõem dos recursos necessários para bem viver. A desterritorialização do conceito de comunidade significa que não há necessariamente coincidência entre conceito e localidade como espaço de moradia, como, por exemplo, um bairro, já que, para o autor, comunidade são os vínculos duradouros e compromissos assumidos que forjam uma coletividade.

Seguindo-se essa linha de argumentação, a comunidade pode ser pensada em termos de relações comunitárias que criam raízes dos indivíduos em coletivos e territórios, impulsionando a relação com outros grupos sociais. A sustentabilidade desse sentido de comunidade requer a interação e a experiência social de seus membros na vivência cotidiana de consensos e conflitos (SANTOS, 2002) e indica a presença da elaboração de alternativas como forma de enfrentar as dificuldades:

Na comunidade as experiências político-sociais e culturais populares da pluralidade das desigualdades cotidianas e contradições do sistema emergem como conflitos, solidariedades e alternativas que melhorem a vida das pessoas (COSTA, 2006, p. 70). 
Esses termos definidores de comunidade podem ser observados em sua função estratégica, no cotidiano dos jovens do movimento Hip-Hop, que articula ações locais desenvolvidas por crews - palavra em inglês que significa grupo, membro, integrante, a crew pode ser entendida como território que exprime uma intervenção mais ampla e coletiva - assentadas em bairros específicos, que também dialogam com um território ampliado. A transposição do local é garantida pelos laços de fraternidade e solidariedade, que caracterizam a sociabilidade coletiva de caráter inevitavelmente político. Nesses termos, propomo-nos a dialogar com a divisão estabelecida por Bauman (2003) entre comunidade estética e ética, segundo a qual a primeira denominação designa laços de natureza efêmera entre seus participantes. A comunidade ética, por sua vez, designa responsabilidades e vínculos duradouros, "compromissos a longo prazo" (BAUMAN, 2003, p. 67), em um esforço de garantir ou o compromisso de construir um mínimo de certeza, segurança e proteção aos indivíduos.

Entendemos que há simultaneamente uma relação e uma tensão entre comunidade estética e comunidade ética na experiência comunitária do movimento Hip -Hop. Há muitos pontos de controvérsia para serem explorados no estudo desse tema, ocupando-se, por exemplo, do viés de expressão de gênero, diálogo com o Estado, participação em partidos políticos, mas, sobretudo, acerca da sua participação mercadológica na indústria cultural. O movimento Hip-Hop articula projetos individuais com projetos coletivos, quando a comunidade estética - a inserção de indivíduos na indústria cultural - é um ponto de passagem, sustentado pela comunidade ética e por seu projeto coletivo. À medida que prevalece o projeto individual, a comunidade estética é um ponto de chegada, que suplanta o projeto coletivo da comunidade ética.

A diversidade de arranjos possíveis entre a ética e a estética tem marcado a contemporaneidade do movimento Hip-Hop. No entanto, o que percebemos é a pertinência da presença dos termos "ética", "coletividade" e "público" naquilo que melhor caracteriza o movimento Hip-Hop como movimento social, aciona territórios e constrói comunidades para enfrentar a lógica da desagregação, da desigualdade e da fragilidade das políticas públicas, em prol da formulação de alternativas para o desenvolvimento dos jovens envolvidos nesse movimento.

\section{Conhecendo e Problematizando a Ação Político-Cultural no Território}

Mangue vem dos manguezais, da sua biodiversidade que faz com que essas áreas se constituam em grandes "berçários" naturais, que aqui encontram as condições ideais para reprodução, eclosão, criadouro e abrigo, quer tenham valor ecológico ou econômico e comunitário, e "Crew" vem de grupo, bando, coletivo, como pode ver no mangue somos um berçário humano (C1).

Para entender a configuração das ações político-culturais no âmbito do movimento Hip-Hop, fizemos uma imersão em certa localidade de manguezal da cidade 
de Recife, que trouxe à tona elementos para refletirmos acerca desse diálogo entre movimento social e comunidade. Os manguezais têm forte presença na constituição geográfica e humana da cidade, e foram citados pioneiramente por Josué de Castro em Homens e caranguejos (1967), que desvela a face da desigualdade social a partir das relações com o mangue.

Localizado na RPA 5, Zona Sudoeste da cidade (que compreende dezesseis bairros), na microrregião 5.3, o bairro em que desenvolvemos parte da pesquisa é o menor do Recife, tem apenas 15 hectares e conta com 601 domicílios e 2.265 habitantes. Essa mesma população reside em áreas classificadas como de interesse social. A renda média dos moradores responsáveis por domicílio gira em torno de $\mathrm{R} \$ 371,97$ (IBGE, 2000). Em relação às outras unidades de desenvolvimento humano do Recife, sua unidade espacial apresenta situação intermediária, pois ocupa a $29^{a}$ posição, e 28 unidades de desenvolvimento humano $(45,2 \%)$ estão em situação melhor e 33 unidades de desenvolvimento humano $(53,2 \%)$ estão em situação pior ou igual (ADHR, 2005).

No Atlas do Desenvolvimento Humano da cidade de Recife (2005), o total da população jovem residente na localidade, por faixa etária, apresenta-se como mostra o quadro abaixo:

\begin{tabular}{c|c} 
FAIXA ETÁRIA & POPULAÇÃO \\
\hline 10 a 14 anos & 229 \\
\hline 15 a 17 & 121 \\
\hline 18 a 22 & 207 \\
\hline 23 a 24 & 72 \\
\hline Total & 629
\end{tabular}

Se levarmos em conta a população total do bairro, que corresponde a 2.265 habitantes, e o total de 629 jovens, teremos uma população jovem que representa $27,77 \%$ da população total. Os jovens da comunidade em tela vivem em um cenário de desigualdade social, vulnerabilidade, baixa renda per capita e precário acesso à educação e a serviços de saúde. Nesse contexto, encontramos assentada uma das crews do movimento Hip-Hop da cidade de Recife, com atuação prioritária junto a jovens e crianças do bairro.

De acordo com pesquisas da área, a peculiaridade brasileira desse "pedaço" no bairro residiria no arco amplo de atividades que desenvolve com caráter político, voltadas para aspectos organizativos da ação e do movimento Hip-Hop na localidade.

A crew investigada autodenomina-se Coletivo e, durante o período de acompanhamento de suas atividades (junho e novembro 2008), desenvolveu, junto a trinta crianças e adolescentes de baixa renda da comunidade e das circunvizinhanças, ações diversas. Seus integrantes se intitulam "educadores de rua" e realizaram, desde o começo de 2008, o Projeto Artístico para o Desenvolvimento Social: da Lama ao Mundo. Em sua sede, eles realizam oficinas de fotografia, grafite, break e outras danças. O entrevistado J1 afirma: 
Ao longo dos anos a [...] crew vem conquistando um bom espaço em Recife, atuando em várias comunidades com seu trabalho voluntário, em locais como a escola IEP e FUNDAC entre outros, tendo ainda como um dos maiores focos sua comunidade de origem.

Para além do projeto acima exposto, a crew busca aproximação com os moradores em geral, por meio da organização de festas em datas comemorativas: São João, Dia das Crianças, Natal, e exposições diversas: Semana Cultural de Artes Visuais na Comunidade, fotografia, exibição de documentários, apresentações de teatro, raps, rodas de capoeira, apresentações de break e dança afro. No caso do mutirão de grafite, além da aproximação, também são observadas duas outras funções: uma diz respeito a positivar a "imagem" do grafite e a outra, a produzir um momento de intercâmbio e encontro entre os jovens do movimento de outras localidades.

Ainda no mutirão, ocorre certo "ritual" de dupla aproximação, pois, antes das atividades, há um diálogo entre os integrantes da crew e os outros jovens do movimento (discutem a definição dos muros e da dinâmica do almoço coletivo, compartilham informações e deliberam sobre o próximo mutirão, falam do que trata o evento e da importância dele para o território). A outra aproximação dá-se com os moradores para utilização de seus muros, quando é possível entabular outros diálogos, a exemplo da encomenda de alguns sobre tipos de grafite que gostariam de ver estampados em seus muros. Outros moradores apenas observam de suas calçadas e dos arredores o que acontece.

Com o propósito de entender a capacidade de intervenção cultural, política e subjetiva da crew, considerando níveis de análise sua repercussão na vida dos jovens integrantes, na vida dos jovens em geral e na vida no bairro, recorremos a observações e acompanhamento de atividades, conversas informais e entrevistas. Participaram desse momento lideranças de outros movimentos, membros da localidade (jovens e adultos) e jovens integrantes da crew.

Com a análise do material registrado, propomos algumas problematizações sobre a relação da crew com o conjunto de moradores, o diálogo com outros movimentos existentes no bairro, acerca dos limites da ação do próprio movimento Hip-Hop e dos riscos implicados na invasão de territórios já demarcados, a exemplo do tráfico de drogas.

Os limites da ação do movimento Hip-Hop podem ser problematizados a partir da vivência geracional - do ser jovem - na sociedade. É comum compreender a juventude como um vir-a-ser, uma fase antiprodutiva, incapaz de intervir na realidade, fase que antecede e prepara a entrada no mundo adulto. A respeito disso Dayrell afirma que:

[...] nos deparamos no cotidiano com uma série de imagens a respeito da juventude que interferem na nossa maneira de compreender os jovens. Uma das mais arraigadas é a juventude vista na sua condição de transitoriedade, na qual o jovem é um "vir- 
a-ser", tendo no futuro, na passagem para a vida adulta, o sentido das suas condições no presente. [...] tende-se a negar o presente vivido do jovem como espaço válido de formação, assim como as questões existenciais que eles expõem, bem mais amplo do que apenas o futuro (DAYRELL, 2003, pp. 40-1).

Essa imagem acerca da juventude dificulta o diálogo e a construção de relações sociais entre jovens e adultos. Na localidade investigada, encontramos pelos menos três posicionamentos com relação ao movimento Hip-Hop, que indicam: 1) o desconhecimento; 2) a desqualificação; e 3) a abertura para o diálogo ou credibilidade.

Com relação ao primeiro posicionamento, havia entrevistados que desconheciam o assentamento territorial da crew: "Olhe, eu nem sabia que eles tinham uma sede", e o teor do trabalho: "Eles passaram aqui um dia me questionando se podiam usar o muro, aí eu disse que poderia, eu autorizei. Eles vieram em um dia de domingo e fizeram esse belo trabalho aí" (M., 56 anos). Concomitantemente ao desconhecimento, vale registrar que havia quem afirmasse a presença das ações: "Eu via os eventos que eles fazem. De vez em quando eles fazem" (L., 24 anos).

Contudo, nem sempre tais atividades são bem recebidas, dado o preconceito com relação às iniciativas dos membros da crew com diferentes modos de desqualificação, como se percebe pelo teor depreciativo atribuído às ações: "participa, mas participa mal, ela tem que participar bem. Tá certo que aí tem eventos, tem brincadeiras" (A., 32 anos). Nesse caso, o que está em questão é a associação entre a condição juvenil (irresponsabilidade) e a ação consequente (para os adultos).

Do ponto de vista dos adultos, que tomam como referência de transformação mudanças na infraestrutura local, os depoimentos indicam ausência desse tipo de intervenção realizada pelos jovens, o que configura para eles sua ineficácia: "Até o momento, os trabalhos realizados por eles só foram trabalhos direcionados para eles, pintar muros, pintar fachadas. Se o trabalho deles fosse em realizar, limpar canaletas, antes de pintar, aí teria ajudado o pessoal da rua, quanto ajudar a imagem deles" (A., 32 anos). Com isso, atribui-se responsabilidades aos jovens que, sobretudo, são inerentes ao poder público, como se isso fosse condição de credenciamento de suas ações.

Há ainda situações de desqualificação do jovem do movimento Hip-Hop, relatadas por liderança de outro movimento, que indicam presença de conflito geracional, cuja ênfase retoma frequentemente a ideia de despreparo: "Tem gente que tem aquilo como um antro de maconheiro. Já eu não tenho essa visão, porque eu sou jovem, mas os mais velhos não gostam" (A, 32 anos).

Como repercussão da desqualificação, as expressões de preconceito e discriminação, por parte de lideranças de outros movimentos, também provocam certo distanciamento, o que impede a união em favor do enfrentamento das problemáticas que afetam a todos:

Eu já vi algumas apresentações deles aqui no bairro. Eu não conheço totalmente, porque a gente fica mais voltado pra o trabalho 
humanitário e a [...] crew é um trabalho mais sociocultural, e a gente age diretamente na parte do bem-estar da comunidade, em relação a alimentação, saúde (C., 48 anos).

Esse posicionamento está orientado por uma visão cindida de ação coletiva, uma vez que a separa da ação sociocultural, valorizando a primeira em detrimento da segunda, como se esta não pudesse produzir benefícios à coletividade. Tal perspectiva colabora para alimentar a fragmentação, desfavorece ações conjuntas e contínuas: "A minha contribuição foi dar o muro, mas depois ninguém me procurou mais [...]" (M., 56 anos).

Por fim, encontramos abertura para o diálogo e atribuição de credibilidade ao movimento, a exemplo da disposição para o encontro: "Se eles me procurarem, eu vou dar todo o apoio. O que eu puder fazer eu faço" (O., 39 anos). Há certa credibilidade quando o morador do bairro enfatiza a relevância do trabalho: "O trabalho deles é importante, poderia oferecer um curso que muita gente ia participar. la ser divulgado o trabalho, que é um trabalho de educação" (O., 39 anos).

Desconhecimento, desqualificação, abertura-ausência de diálogo e credibilidade convergem para um entendimento cristalizado, ainda predominante acerca da juventude, como inapta à participação político-social. São posturas implícitas nas práticas sociais e perceptíveis aos jovens, que os colocam na defensiva. Outro aspecto a ser observado é a perspectiva tradicional sobre ação político-social, que desconsidera possíveis inovações no campo da ação coletiva, o que dificulta a articulação da crew com outros movimentos em prol do território.

A participação e organização juvenil em movimentos sociais, como é o caso do Hip-Hop, poderia modificar as relações de poder estabelecidas no âmbito local. No entanto, os jovens membros do movimento não têm enfrentado o conflito existente entre a percepção que os moradores de suas localidades têm acerca do potencial juvenil para ações coletivas que possam produzir transformações sociais e o que de fato é operado nessa direção.

O exercício da política nos territórios em que o movimento Hip-Hop atua poderia provocar a constituição de novas relações sociais, a partir da instauração desse tipo de conflito, trazer à tona formas de poder implicadas no modo como o movimento é visto nesses cenários, ao tempo em que caminharia para a construção de outra cultura política mais aderente à participação dos jovens e o diálogo entre as gerações. Com isso, percebemos que "o político não é algo que tem um lugar específico e determinado na sociedade e que todas as relações sociais podem se tornar o lócus dos antagonismos políticos" (MOUFFE, 2003, p. 13). Falta aos jovens entendimento e apropriação desse tipo de exercício da vida pública, sentido último da política.

Em um outro nível de problematização, temos a relação entre o movimento Hip-Hop e outros movimentos sociais existentes nos territórios, que encaram o Hip-Hop como ação restrita à dimensão cultural:

[...] eu acho melhor participar de uma ação de compreensão com a comunidade [...]. A gente que é um pouco mais velho, a 
gente tá olhando para o futuro, planejamento de rua, planejamento de linha de ônibus pro bairro. Participo do orçamento participativo, eu cobro de quem eu elegi (A., 32 anos).

Isso denota certa clivagem entre os segmentos tradicionais de política dos movimentos associativos e os jovens mencionados no contexto do próprio bairro o que parece colaborar para o distanciamento entre os jovens do movimento HipHop e outros movimentos sociais.

Por outro lado, localizamos iniciativas de aproximação: "Olha, eu fui até eles e disse: 'Não, isso tem que ter aqui, a gente têm um espaço lá, chegue lá pra visitar o espaço nosso e vejam se vocês se adaptam ao espaço, eles vieram, gostaram [...]" (I, 33 anos). O que se propunha no momento era compartilhar espaço físico para o desenvolvimento de atividades (dança, grafite etc.). Nesse caso, o interesse do outro movimento era atrair os jovens do Hip-Hop para militarem em outra causa (ambiental).

Observamos, entretanto, certa dificuldade de relacionamento ou de diálogo entre o movimento Hip-Hop e outros movimentos existentes nos territórios em que ele atua. Aventamos diversas hipóteses explicativas, embora não pretendamos no momento nos arriscar prematuramente a defender nenhuma delas. $O$ fato é que esse proceder dificulta ações consistentes em termos de transformação da vida nos territórios em que tais movimentos se situam.

Outro aspecto a se considerar tem a ver com as diversas carências enfrentadas pelo movimento para concretizar ações, especialmente a ausência de recursos que favoreceriam a expansão dos trabalhos educativos, como a já mencionada falta de local que sirva de ponto de apoio para seu desenvolvimento. Os próprios jovens também enfrentam dificuldades de sobrevivência e a maioria vive em insegurança econômica, com trabalhos instáveis e informais. Eles utilizam os potenciais desenvolvidos no movimento Hip-Hop como fonte de renda, como a pintura, trabalho com arte-educação, entre outros.

Há também que se negociar com as gangues e com o tráfico existentes nos territórios para a concretização de algumas ações, porque há risco de o movimento invadir as áreas de domínio dos primeiros, o que pode comprometer a integridade dos jovens. Há necessidade de cuidado, já que, de qualquer modo, a ação do movimento Hip-Hop se direciona em sentido contrário aos desses grupos, ou seja, impedir que jovens entrem no mundo das drogas e, por vezes, retirá-los desse mundo.

\section{Território das Desigualdades Sociais: É Possível Produzir Comunidade?}

O movimento Hip-Hop produz vínculos e compromissos de longo prazo e um campo de ação político-cultural que sugere a constituição de comunidade pautada em princípios ético-políticos. Entretanto, enfrenta os limites aqui expostos: 1) predominância do imaginário negativo acerca da condição juvenil; 2) escassos recursos materiais disponíveis; e 3) dificuldade de diálogo e de negociação com outros atores sociais. Esse quadro dificulta sua colaboração para o desenvolvimento territorial, repercute em seu escopo de ação e acaba por limitá-lo ao segmento infanto-juvenil, em razão de maior aceitação e apelo junto a essa população. Desse 
modo, pode-se perguntar: o que mobiliza os jovens do movimento Hip-Hop a crer na possibilidade de construir comunidade e com ela potencializar desenvolvimento territorial?

Afora os elementos artísticos comumente difundidos pelo Hip-Hop, o quinto elemento - o conhecimento - atua como cimentador de uma orientação ético-política que alimenta posicionamentos críticos e mobiliza o segmento juvenil para a produção de uma identidade coletiva, com uma nova cultura política, que visa a gerar comunidade, empoderar os jovens e colaborar para a superação das dificuldades presentes em seu cotidiano.

Para Zeni:

A conscientização compreende principalmente a valorização da ascendência étnica negra, o conhecimento histórico de luta dos negros e de sua herança cultural, o combate ao preconceito racial, a recusa em aparecer na grande mídia e o menosprezo por valores como a ganância, a fama e o sucesso fácil (2004, p. 230).

Nesses termos, é possível reconhecer nos discursos e práticas o engajamento por meio da ação político-cultural, como modo de acionar a partilha de bens simbólicos produzidos pelo grupo com membros do território, no sentido de gerar o desenvolvimento de potenciais que contribuam para o alcance de outros patamares de existência:

Assim, mudou na questão de ver os problemas sociais tipo na minha comunidade, e através disso eu vou até participar de um projeto na associação e usar o grafite pra uma forma de educação ou até de profissionalismo para as pessoas (C., 26 anos).

Pode acontecer, acho que até tem vários grupos que usam o grafite como movimento social, pra, através do grafite, educar as pessoas. Pronto, eu acho que a partir daí, quando usa esse movimento pra educar, pra tentar mudar o indivíduo, eu acho que por aí já muda (J., 22 anos).

Os jovens envolvidos no movimento reconhecem em si certas vantagens em relação a outros jovens dos bairros em que residem, como o conhecimento acerca da realidade e o desenvolvimento de novas habilidades. Eles sentem-se responsáveis e assumem o compromisso de compartilhar tal conhecimento e habilidades com esses outros jovens, à medida que desenvolvem ações em seus territórios.

Muitos grupos, como o Coletivo Êxito D'Rua (2008), divulga em blog os objetivos do movimento em direção à necessidade de politização de outros jovens:

Através da cultura Hip-Hop e de suas manifestações artísticas e sociopolíticas, despertar nos adolescentes e jovens das comunidades a ação independente e positiva na sociedade, bem como 
\} Os Territórios de Ação Política de Jovens do Movimento Hip-Hop - COSTA, R. C. \& MENEZES, J. A. \}

a conscientização, que a comunidade pense, trabalhe, se organize para discutir os seus problemas e encontrar soluções.

Ao propor uma ação reflexiva que encontre soluções para os problemas, o movimento impulsiona os jovens a desenvolverem uma relação de outra natureza com seus locais de moradia. Dessa forma, esses jovens veem no Hip-Hop um potencial político transformador de caráter educativo, que também provoca mudanças nas pessoas. Com isso, cria novas possibilidades de ser e estar em coletividade. 


\section{Referências Bibliográficas:}

ADHR. Atlas do desenvolvimento humano do Recife. Recife, 2005. Disponível em http://www.recife.pe.gov.br. Acesso em 13 de outubro. 2008.

APS. Geografia dos Subúrbios. Álbum Dialeto Sonoro Contemporâneo, In-Bolada Records, v. 1, 2005.

ARAÚJO, Tânia B. Território, desenvolvimento rural e regional. Território, desenvolvimento rural e democracia. Anais do I Fórum Internacional. Fortaleza, 2003. ARRUDA, Marcos. Globalização e desenvolvimento comunitário autogestionário. In: ARRUDA, Marcos. Globalização: desafios socioeconômicos, éticos e educativos. Petrópolis: Vozes, 2001.

BAUMAN, Zygmunt. Comunidade: a busca por segurança no mundo atual. Rio de Janeiro: Jorge Zahar, 2003.

BONNEMAISON, J. e CAMBREZY, L. Le lien territorial: entre frontières et identités. Géografhies et Cultures. Paris: L'Harmattan-CNRS, 20, 1996. CASTRO, Josué de. Homens e caranguejos. São Paulo: Brasiliense, 1967. COLETIVO ÊXITO D'RUA. Disponível em http://www.in-boladarecord.blogspot. com/. Acesso em 15 de junho. 2008.

COSTA, Mônica R. e MENEZES, Jaileila A. Projeto de pesquisa: a arte na política: um estudo do movimento Hip Hop na cidade de Recife. Recife: UFPe, 2007.

COSTA, Mônica R. Experiências emancipatórias, alternativas políticas e políticas alternativas dos movimentos sociais no Nordeste. Recife,Tese de Doutorado, Universidade Federal de Pernambuco, 2006.

DAYRELL, Juarez. O jovem como sujeito social. Revista Brasileira de Educação, n. 24. São Paulo: Associação Nacional de Pós-graduação e Pesquisa em Educação, 2003, pp. 40-53.

FOLHATEEN. Folha de S. Paulo, 20 de novembro. 2006.

HAESBAERT, Rogério. Concepções de território para entender a desterritorialização. In: SANTOS, M. Território, territórios: ensaios sobre ordenamento territorial. 3. ed. Rio de Janeiro: Lamparina, 2007.

IBGE. INSTITUTO BRASILEIRO DE GEOGRAFIA E ESTATÍ́STICA . Rio de janeiro: IBGE, 2000.

MOUFFE, Chantal. Democracia, cidadania e a questão do pluralismo. Revista Política \& Sociedade, v. 1, n.3. Florianópolis: UFSC, 2003.

RACIONAIS MC's. Periferia é Periferia. Álbum Sobrevivendo no Inferno, 1998. REZENDE, Valéria. Ninguém pode servir a dois senhores. São Paulo: Ed. Paulinas, 1987.

RODRIGUES, Glauco B. Uma geografia do Hip-Hop. Niterói: Monografia de Conclusão de curso do Departamento de Geografia da Universidade Federal Fluminense, 2003.

SANTOS, Boaventura de Sousa. A crítica da razão indolente: contra o desperdício da experiência. São Paulo: Cortez, 2002.

SANTOS, Milton. Por uma outra globalização: do pensamento único à consciência universal. Rio de Janeiro: Ed. Record, 2001 
SILVA, Jailson de S. e BARBOSA, Jorge L. Favela: alegria e dor na cidade. Rio de Janeiro: Ed. SENAC, 2005.

SILVA, Jailson de S. Um espaço em busca de seu lugar: as favelas para além dos estereótipos. In: SANTOS, M. Território, territórios: ensaios sobre ordenamento territorial. 3 ed. Rio de Janeiro: Lamparina, 2007.

UNESCO. Mapa da violência IV. Brasília, 2005. Disponível em http://www. unesco.org.br/servicos/pesquisa/mapadaviolencia4. Acesso em 15 de setembro. 2008.

UNESCO. Relatório de desenvolvimento juvenil. Brasília, 2003. Disponível em http://www.unesco.org.br/servicos/pesquisa/idj2003. Acesso em 15 de setembro. 2008.

ZENI, Bruno. O negro drama do rap: entre a lei do cão e a lei da selva. Revista Estudos Avançados, Dossiê O Negro no Brasil, n. 50. São Paulo: USP, 2004. ZULU NATION BRASIL. Disponível em http://www.zulunationbrasil.com.br/. Acesso em 22 de outubro. 2008.

Recebido em 03 de agosto de 2009.

Aceito para publicação, em 20 de outubro de 2009. 